Review

\title{
Review of investment model cost parameters for VSC HVDC transmission infrastructure
}

\author{
Philipp Härtel ${ }^{a, *}$, Til Kristian Vrana ${ }^{b}$, Tobias Henniga ${ }^{a}$, Michael von Bonin ${ }^{a}$, \\ Edwin Jan Wiggelinkhuizen ${ }^{c}$, Frans D.J. Nieuwenhout ${ }^{c}$ \\ a Fraunhofer IWES, Kassel, Germany \\ b SINTEF Energi, Trondheim, Norway \\ c ECN, Petten, The Netherlands
}

\section{A R T I C L E I N F O}

\section{Article history:}

Received 15 December 2016

Received in revised form 10 May 2017

Accepted 11 June 2017

\section{Keywords:}

Offshore grids

Transmission expansion planning

Cost model

HVDC

VSC

\begin{abstract}
A B S T R A C T
Cost parameters for VSC HVDC transmission infrastructure have been gathered from an extensive collection of techno-economic sources. These cost parameter sets have been converted to a common format, based on a linear investment cost model depending on the branch length and the power rating of cable systems and converter stations. In addition, an average parameter set was determined as the arithmetic mean of the collected parameter sets, and included in the study. The uniform format allowed for a comparison of the parameter sets with each other, which revealed large differences between the cost parameter sets. The identified disparity between the parameter sets reflects a high level of uncertainty which can only in part be explained by a varying focus and modelling approach of their sources. This implies limitations regarding the validity of the parameters sets as well as of the results from grid expansion studies carried out on the basis of these parameter sets.

Comprehensive cost reference data has been collected from realised and contracted VSC HVDC projects (back-to-back, interconnector, and offshore wind connection). The cost parameter sets have been evaluated against the reference project cost data. This evaluation has again shown large variations between the parameter sets. On average, the cost for back-to-back systems are slightly underestimated, interconnectors are overestimated, and offshore wind connections are heavily underestimated. To clearly state the validity and limitations of this comparison and evaluation, the applied methodology with its compromises and drawbacks is discussed in detail. Considering the interest in and momentum of offshore grid development, as well as the number of offshore grid investment and evaluation studies being conducted, both the availability of reliable cost reference data and the validity of investment model cost parameters need continuing attention.
\end{abstract}

(C) 2017 Elsevier B.V. All rights reserved.

\section{Contents}

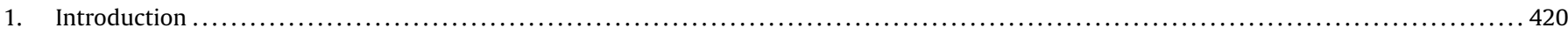

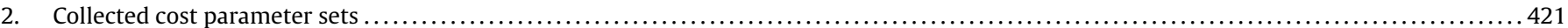

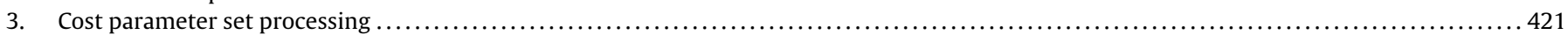

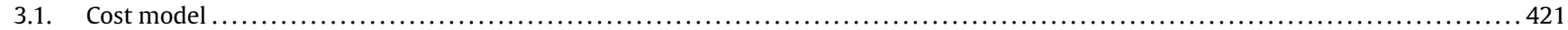

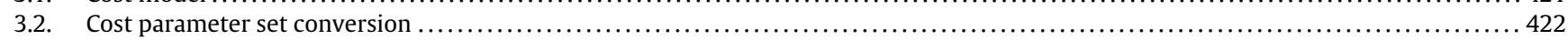

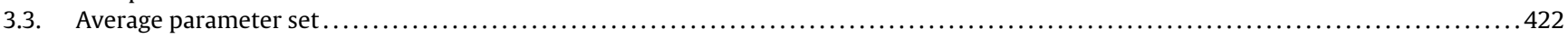

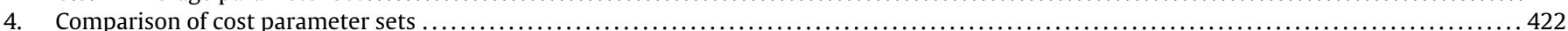

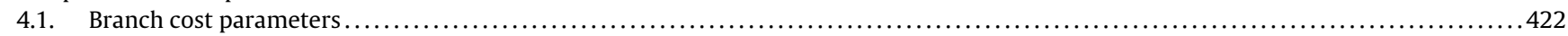

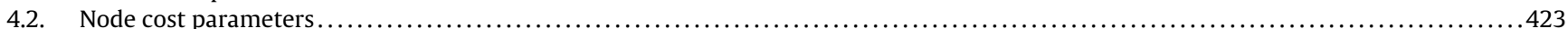

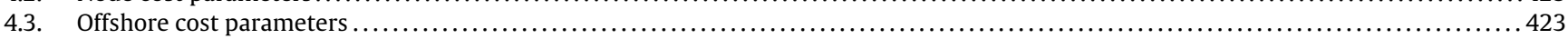

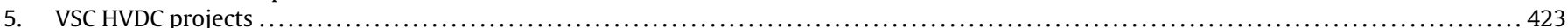

\footnotetext{
* Corresponding author.

E-mail address: philipp.haertel@iwes.fraunhofer.de (P. Härtel).
} 


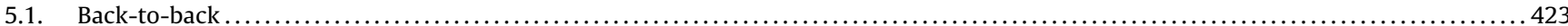

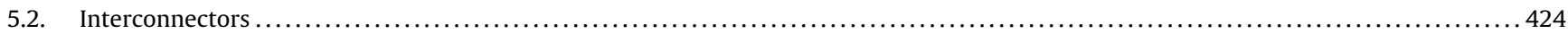

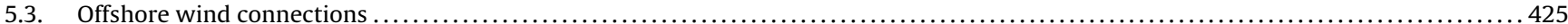

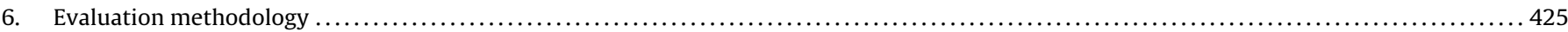

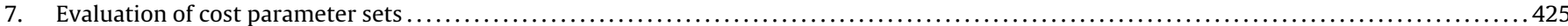

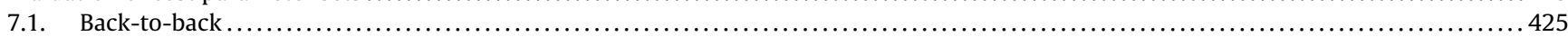

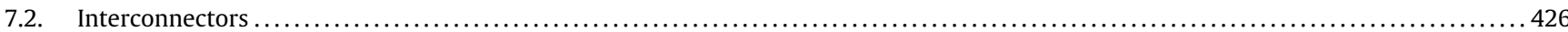

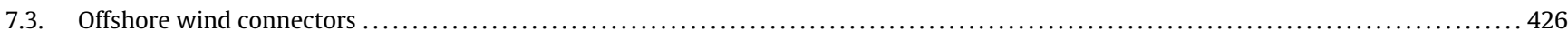

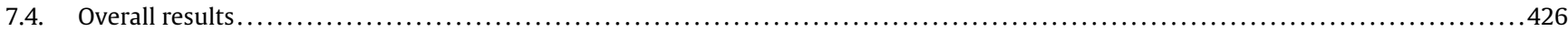

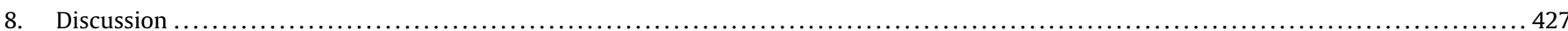

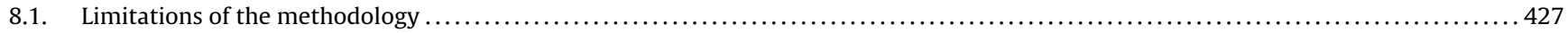

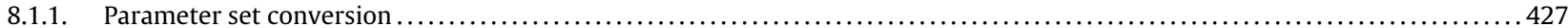

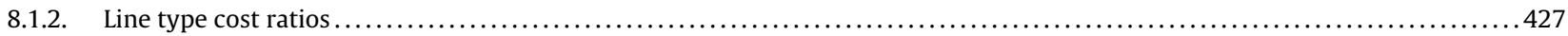

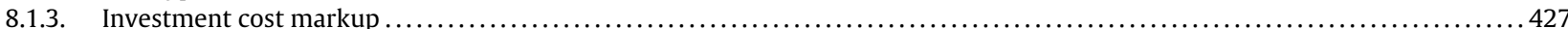

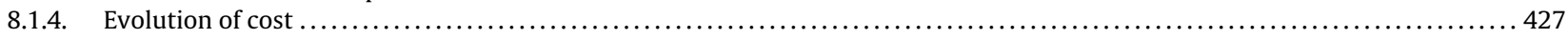

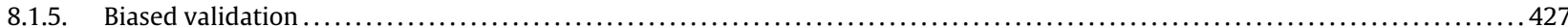

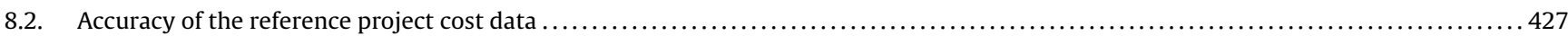

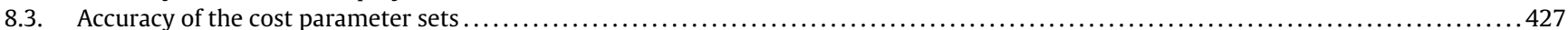

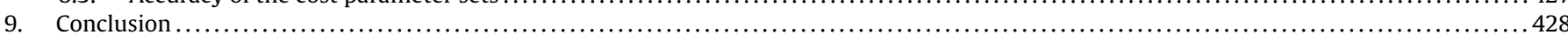

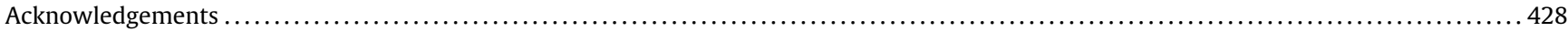

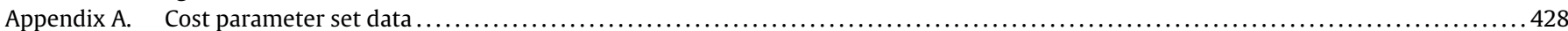

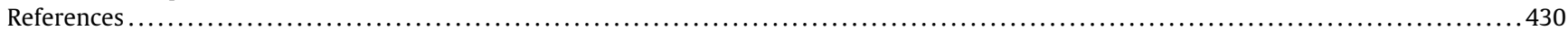

\begin{tabular}{|c|c|}
\hline \multicolumn{2}{|c|}{ Nomenclature } \\
\hline \multicolumn{2}{|c|}{ Abbreviations } \\
\hline $\mathrm{B} 2 \mathrm{~B}$ & Back-to-back \\
\hline ITC & Interconnector \\
\hline OWC & Offshore wind connection \\
\hline \multicolumn{2}{|c|}{ General } \\
\hline$\lceil$ real $\rceil$ & Ceiling of real $\left(\lceil\right.$ real $\rceil=\min \left\{n \in \mathbb{N}_{0} \mid n \geq\right.$ real $\left.\}\right)$ \\
\hline $\mid$ set $\mid$ & Cardinality of set \\
\hline \multicolumn{2}{|c|}{ Indices and sets } \\
\hline$f \in F_{i}$ & Set of branches within project $i$ \\
\hline$g \in G_{i}$ & Set of nodes within project $i$ \\
\hline$h \in H_{i}$ & Set of offshore nodes within project $i$ \\
\hline$i \in I_{j}$ & Set of projects within category $j$ \\
\hline$j \in J$ & Set of project categories $(J=\{B 2 B, I T C, O W C\})$ \\
\hline$k \in K$ & Set of cost parameter sets \\
\hline \multicolumn{2}{|c|}{ Cost parameters and variables } \\
\hline$B_{0}^{k}$ & $\begin{array}{l}\text { Fixed cost for building a branch with cost parameter } \\
\text { set } k(\mathrm{M} €)\end{array}$ \\
\hline$B_{l p}^{k}$ & $\begin{array}{l}\text { Length- and power-dependent cost for building a } \\
\text { branch with cost parameter set } k(\mathrm{M} € / \mathrm{GW} \mathrm{km})\end{array}$ \\
\hline$B_{l}^{k}$ & $\begin{array}{l}\text { Length-dependent cost for building a branch with } \\
\text { cost parameter set } k(\mathrm{M} € / \mathrm{km})\end{array}$ \\
\hline$C_{\mathrm{est}, i}^{k}$ & Estimated investment cost for project $i(\mathrm{M} €)$ \\
\hline$C_{\mathrm{ref}, i}$ & Reference investment cost for project $i(\mathrm{M} €)$ \\
\hline$C_{\mathrm{ref}, i}^{\mathrm{con}}$ & Reference contracted cost for project $i(\mathrm{M} €)$ \\
\hline$N_{0}^{k}$ & $\begin{array}{l}\text { Fixed cost for building a node with cost parameter } \\
\text { set } k(\mathrm{M} €)\end{array}$ \\
\hline$N_{p}^{k}$ & $\begin{array}{l}\text { Power-dependent cost for building a node with cost } \\
\text { parameter set } k(\mathrm{M} € / \mathrm{GW})\end{array}$ \\
\hline$S_{0}^{k}$ & $\begin{array}{l}\text { Fixed additional cost for building an offshore node } \\
\text { with cost parameter set } k(\mathrm{M} €)\end{array}$ \\
\hline$S_{p}^{k}$ & $\begin{array}{l}\text { Power-dependent additional cost for building an } \\
\text { offshore node with cost parameter set } k(\mathrm{M} € / \mathrm{GW})\end{array}$ \\
\hline
\end{tabular}

Technical parameters and variables

$\hat{P}_{j} \quad$ Maximum power rating for a single installation within category $j$ (GW). In case of a back-to-back system, this is twice the system rating (two fully rated converters at one node)

$l_{\mathrm{OHL}, f} \quad$ Overhead line section length of branch $f(\mathrm{~km})$

$l_{\mathrm{SMC}, f} \quad$ Submarine cable section length of branch $f(\mathrm{~km})$

$l_{\mathrm{UGC}, f} \quad$ Underground cable section length of branch $f(\mathrm{~km})$

$l_{f} \quad$ Total equivalent line length of branch $f(\mathrm{~km})$

$p_{f} \quad$ Installed power rating of branch $f(\mathrm{GW})$

$p_{g / h} \quad$ Installed power rating at node $g / h(G W)$. In case of a back-to-back system, this is twice the system rating (two fully rated converters at one node)

Deviations and errors

$D_{i}^{k} \quad$ Project investment cost estimation deviation of project $i$ for cost parameter set $k(-)$

$D_{j}^{k} \quad$ Category investment cost estimation deviation of category $j$ for cost parameter set $k(-)$

$E^{k} \quad$ Overall investment cost estimation error for cost parameter set $k(-)$

$E_{j}^{k} \quad$ Category investment cost estimation error of category $j$ for cost parameter set $k(-)$

\section{Introduction}

Many transmission expansion studies have investigated and optimised the topology of a future North Sea Offshore Network [1]. A solid cost parameter basis, serving as input for the optimisation algorithms, is crucial to producing reliable results in investment planning. As with offshore wind investment cost [2], these types of cost parameters have been widely used by academia and policymakers for assessments and decision support. However, the cost parameters of offshore transmission infrastructure show significant variations from study to study and indicate a high level of uncertainty. Clearly, and also in light of scientific standards, this calls for a cautious and transparent attempt to compare previously used cost parameter sets and evaluate them against real project cost 
data in order to avoid flawed recommendations stemming from grid investment studies.

Voltage Source Converter (VSC) High Voltage Direct Current (HVDC) is the most suitable technology for future super grids in Europe [3]. However, it is a rather new technology, which has seen a significant progress over the last years with many new projects being developed and deployed. Given this context, finding adequate parameter sets yielding valid cost estimates for this type of transmission technology is a challenging task.

This article focuses on essential investment cost. Operation, maintenance and financing costs, as well as additional cost of optional protection devices for increased reliability (DC circuit breakers) are not considered here.

In the remaining part of this article, Section 2 provides a literature overview of the collected cost parameter sets. Section 3 describes the linear cost model used here. In Section 4, the collected cost parameter sets are compared with each other. Section 5 presents realised and contracted VSC HVDC projects, including publicly available cost figures as reference data. Section 6 introduces the evaluation methodology for the validation of cost parameter sets against the reference project data, which is presented in Section 7. Section 8 discusses the obtained comparison and evaluation results and Section 9 concludes the study.

\section{Collected cost parameter sets}

Cost parameter sets for VSC HVDC infrastructure have been widely used and published in the literature. The sources range from technology cost reports, over journal and conference contributions to offshore grid investment reports. Some of these sources are not independent primary sources, as they base their data on other sources listed here.

RealiseGrid [4] compares different interconnection technology options at a national and cross-border level in order to assess techno-economic benefits of transmission expansion. Both HVDC and HVAC cables for submarine and underground application are considered by the project. The data is based on technical and scientific literature, internal knowledge and on questionnaires of TSOs who took part in the project.

Windspeed [5] gives an assessment of transmission costs for the North Sea by taking a closer look at location-specific effects. Different technological and logistical options are considered and a cost methodology is developed for each. To determine the costs, a bottom-up approach is used accounting for weight and material costs of each component. In addition, future developments and learning curves are taken into consideration.

ENTSO-E's technology cost report [6] involves all TSOs from North Sea's Regional group as well as suppliers and manufacturers. The study gives a broad overview of different offshore technology costs and particularly addresses new technology components for offshore transmission such as subsea cables, HVDC converters, and offshore platforms.

Ergun et al. [7] from the University of Leuven develop a software tool in order to determine the economically best and technically feasible way to transmit offshore wind power to shore. Based on data from the previously published literature, the study uses a cost model for cables, transformers, and converter stations.

ETYS13 (the Electricity Ten Year Statement) [8] is a technology report which is annually published by Great Britain's TSO National Grid. With the intention of presenting future investment plans, this source describes a broad range of technical approaches for offshore and onshore transmission technologies, while at the same time providing cost data for most relevant components. The data has been gathered from suppliers of the technology options in question.
NSTG (North Sea Transnational Grid) investigated benefits of an offshore grid connecting all North Sea countries [9,10]. Comparing the results of a bottom-up and a top-down approach, the project derives cost parameters for the assessment of benefits associated with offshore grids.

NSOG [11] was conducted for the European Commission and assesses a range of potential benefits for a meshed offshore grid design in the North Sea, Irish Sea and the English Channel on the background of various scenarios. For the calculation of technoeconomic benefits, investment and O\&M costs of radial and meshed grid designs are analysed with input from previous studies and a consultancy firm.

Imperial College [12] focuses on the North Sea region to calculate the maximum benefit of an interconnected grid design using a minimum regret approach. The underlying cost model makes use of only two parameters to cover all the costs induced by transmission expansion investments.

NorthSeaGrid [13] was a project co-funded by the EU involving many stakeholders to analyse costs, benefits, and barriers for the connection of offshore wind farms and onshore electricity grids. Drawing upon a wide range of sources and stakeholders involved, a broad selection of input data is considered in the cost estimation of offshore grid infrastructure.

OffshoreDC [14] focuses on the benefits of an offshore grid which further integrates electricity markets in the Baltic Sea region. The linear transmission expansion planning approach includes power flow calculations and a simplified cost model to determine the optimal grid design. Input data is based on publicly available literature.

Madariaga et al. [15] from the Offshore Renewable Energy (ORE) Catapult give an overview of existing cost literature from former studies and include inputs from industry consultation to provide cost data for all crucial components. The resulting costs are compared to realised projects, namely BorWin2 and SylWin1.

ETYS15 [16] is the most recent version of the ETYS this review refers to. Following ETYS13 as the earliest version containing a detailed cost compilation for HVDC technology, ETYS15 comprises technology cost data based on updated project information.

Torbaghan [17] from the Delft University of Technology includes a cost model for the offshore grid investigations in his doctoral thesis. Assessing offshore grid investments with a focus on optimisation techniques, the cost model uses only one parameter to cover all costs incurred by offshore transmission investments.

\section{Cost parameter set processing}

There are two motivations why a uniform cost model is indispensable in this context:

- To apply the cost parameter sets in transmission expansion studies.

- To allow for comparison and evaluation of the different cost parameter sets.

Hence, such a uniform cost model is introduced here, which allows the collected cost parameter sets to be converted into a common format, and the calculation of an average parameter set.

\subsection{Cost model}

Transmission grid expansion problems are usually formulated by a set of nodes representing connection points, generators, and load centres, as well as a set of branches representing potential transmission lines between these nodes. The branch length is calculated based on the known bee-line distance between the nodes, either by including a simple markup or with a detailed line route 
definition. An optimisation algorithm identifies the connections to invest in and computes the corresponding transmission capacities, based on a cost model function assigning investment cost parameters to potential nodes and branches.

A linear cost model yields significant benefits for transmission expansion planning problems and the optimisation algorithms solving them, as computation time and convergence face severe challenges when complex cost models are applied. For this reason, the cost model used in this article is linear. This kind of linear model provides an approximation of the investment cost associated with offshore grid HVDC infrastructure and yields a reasonable accuracy regarding long-term large-scale transmission expansion studies. For instance, a detailed justification can be found in [18].

Based on [18,19], the linear unicorn cost model for VSC HVDC transmission investments is defined in Eq. (1):

$C_{\mathrm{est}, i}^{k}=\sum_{f}^{F_{i}} B_{f}^{k}\left(l_{f}, p_{f}\right)+\sum_{g}^{G_{i}} N_{g}^{k}\left(p_{g}\right)+\sum_{h}^{H_{i}} S_{h}^{k}\left(p_{h}\right)$

The specific cost components in Eq. (1) $B_{f}^{k}\left(l_{f}, p_{f}\right), N_{g}^{k}\left(p_{g}\right)$ and $S_{h}^{k}\left(p_{h}\right)$ are specified by Eqs. (2)-(4):

$B_{f}^{k}\left(l_{f}, p_{f}\right)=B_{l p}^{k} \cdot l_{f} \cdot p_{f}+\left\lceil\frac{p_{f}}{\hat{P}_{j}}\right\rceil\left(B_{l}^{k} \cdot l_{f}+B_{0}^{k}\right)$

$N_{g}^{k}\left(p_{g}\right)=N_{p}^{k} \cdot p_{g}+\left\lceil\frac{p_{g}}{\hat{P}_{j}}\right\rceil N_{0}^{k}$

$S_{h}^{k}\left(p_{h}\right)=S_{p}^{k} \cdot p_{h}+\left\lceil\frac{p_{h}}{\hat{P}_{j}}\right\rceil S_{0}^{k}$

It is important to stress that the installed power rating $\left(p_{g}, p_{h}\right)$ corresponds to the total power rating of all converters at a node, which is twice the system rating for a back-to-back system.

For the three considered project categories, the maximum power ratings for a single installation are given in Eq. (5):

$\hat{P}_{\mathrm{B} 2 \mathrm{~B}}=4 \mathrm{GW}, \hat{P}_{\mathrm{ITC}}=2 \mathrm{GW}, \hat{P}_{\mathrm{OWC}}=2 \mathrm{GW}$

The applied values in Eq. (5) are based on [20]. Note that $\hat{P}_{\mathrm{B} 2 \mathrm{~B}}$ is twice the size of $\hat{P}_{\text {ITC }}$ and $\hat{P}_{\text {OWC }}$, since a back-to-back system contains two fully-rated converters. These maximum power ratings are higher than all reference project power ratings, which are considered later in this article. This implies that the ceiling function bracket terms of Eqs. (2)-(4) always become zero or one for these reference projects.

The cost model is designed with a focus on submarine cables (SMC), being the most common line type for VSC HVDC transmission. In order to account for sections of the transmission line which are an overhead line (OHL) or underground cable (UGC), their lengths are converted to a cost-equivalent submarine cable length, as specified by Eq. (6):

$l_{f}=l_{\mathrm{SMC}, f}+\frac{5}{4} l_{\mathrm{UGC}, f}+\frac{2}{3} l_{\mathrm{OHL}, f}$

Note that the numerical values in Eq. (6) are an estimate based on best knowledge and industry consultation. Estimating the branch cost ratios between the different line types is a difficult task, since they may significantly vary from country to country and from project to project. The real cost for overhead lines is particularly hard to estimate as, in theory, they are much cheaper than cables. However, in reality, public opposition in central Europe often shows that building new overhead lines can be impossible, which would correspond to infinite cost. With that in mind, only a rough estimation was feasible in this context, and the assumptions could not be verified due to a lack of available information.
Table 1

Average parameter set.

\begin{tabular}{lrl}
\hline Parameter & Value & Unit \\
\hline$B_{l p}^{\text {avg }}$ & 0.97 & $\mathrm{M} € / \mathrm{GW} \mathrm{km}$ \\
$B_{l}^{\text {avg }}$ & 0.68 & $\mathrm{M} € / \mathrm{km}$ \\
$B_{0}^{\text {avg }}$ & 0.70 & $\mathrm{M} €$ \\
$N_{p}^{\text {avg }}$ & 80.88 & $\mathrm{M} € / \mathrm{GW}$ \\
$N_{0}^{\text {avg }}$ & 28.38 & $\mathrm{M} €$ \\
$S_{p}^{\text {avg }}$ & 93.45 & $\mathrm{M} € / \mathrm{GW}$ \\
$S_{0}^{\text {avg }}$ & 44.81 & $\mathrm{M} €$ \\
\hline
\end{tabular}

\subsection{Cost parameter set conversion}

Primary data for branches and nodes is available in different formats. Most of the publications do not provide parameter sets which exactly match the investment cost model in Eq. (1). In some cases:

- Only a share of the model's parameter options regarding one of the three components are given, (e.g. only $B_{l p}^{k}$ and not $B_{l}^{k}$ or $B_{0}^{k}$ ). This implicitly sets the not specified parameters regarding that component to zero, as no cost have been associated with the phenomena represented by them.

- Only a share of the model's components are given, (e.g. only $B(l$, $p$ ) and $N(p)$ and not $S(p)$ ). This implicitly sets the not specified components to zero, as no cost have been associated with the component.

- None of the aforementioned cost model parameters are obtainable at all, but rather discrete cost options for single VSC HVDC converter stations or cable system components in various formats (e.g. branch cost data is sometimes given for the cross section of the conductor without direct relation to power transfer capability).

Therefore, in several cases, it is necessary to convert the collected cost parameter sets to match the format of the linear cost model used here. The required linear model coefficients have in these cases been derived by means of a linear regression of given cost-power or cost-length relations. Cost parameters that were not created by linear regression are mentioned in the footnote of the corresponding studies. Tables A.1 and A.2 show the compilation of used primary data and converted model parameters for branch, node and offshore costs from the different sources.

\subsection{Average parameter set}

In contrast to only reviewing single parameter sets, it is interesting to assess 'cost parameter sets' as a whole. Therefore, an additional synthetic average cost parameter set has been calculated as the arithmetic mean of all the collected cost parameter sets. The average parameter set is presented in Table 1.

\section{Comparison of cost parameter sets}

In this section, all the collected parameter sets (summarised in Tables A.1 and A.2) and the average parameter set (specified in Table 1) are compared.

\subsection{Branch cost parameters}

Fig. 1 presents the cost parameters $B_{l p}^{k}, B_{l}^{k}$ and $B_{0}^{k}$, that represent the branch cost part of the investment model, specified in Eq. (2). It can be observed that sets with a high $B_{l p}^{k}$ generally show a lower $B_{l}^{k}$ and vice versa. 

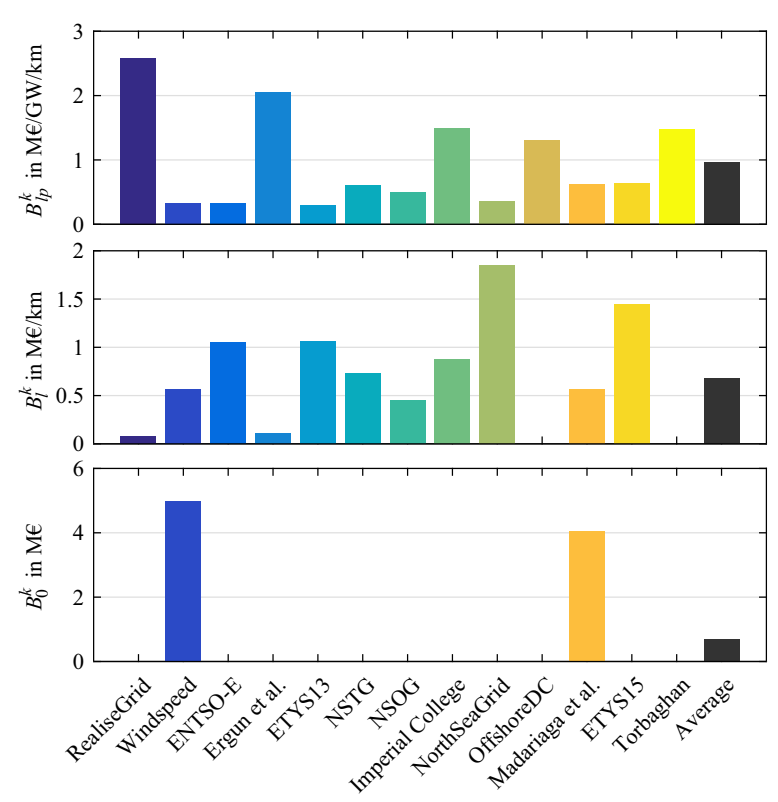

Fig. 1. Comparison of branch cost parameters $B_{l p}^{k}, B_{l}^{k}$ and $B_{0}^{k}$.
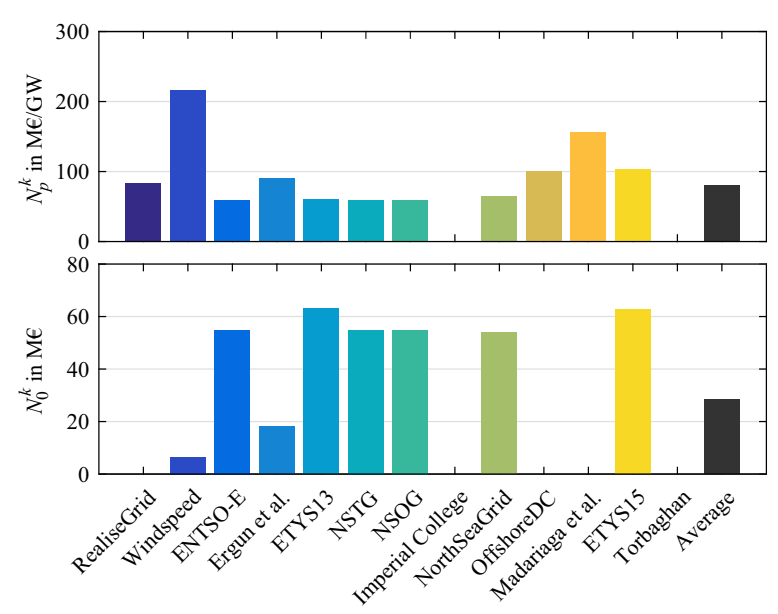

Fig. 2. Comparison of node cost parameters $N_{p}^{k}$ and $N_{0}^{k}$.

\subsection{Node cost parameters}

Fig. 2 presents the cost parameters $N_{p}^{k}$ and $N_{0}^{k}$ constituting the node cost part of the investment model, specified in Eq. (3).

Torbaghan and Imperial College do not provide separate node costs, leading to both $N_{p}^{k}$ and $N_{0}^{k}$ being zero. In theory, it is conceivable that the node cost could be included in the branch's fixed cost $B_{0}^{k}$. However, $B_{0}^{k}$ is small or zero for all considered parameter sets, implying that this effect is not relevant here. Coupled with those two sources' $B_{0}^{k}$ parameter being zero, their resulting cost function is only proportional to the transmission length with no offset. Therefore, these two parameter sets always estimate the cost of a back-to-back HVDC station to be zero, which clearly highlights the drawbacks of such a simplified approach.

\subsection{Offshore cost parameters}

Fig. 3 presents the cost parameters $S_{p}^{k}$ and $S_{0}^{k}$, that represent the additional offshore cost part (deployment at sea) of the investment model, specified in Eq. (4).

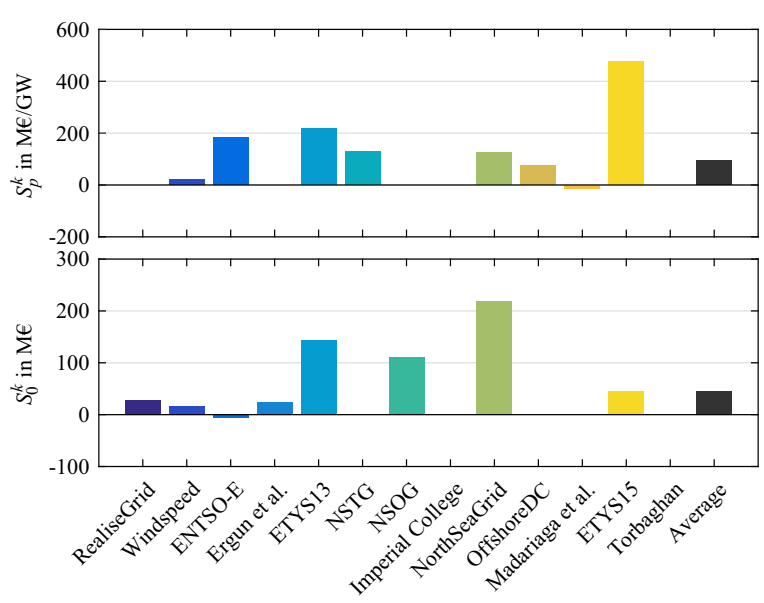

Fig. 3. Comparison of offshore cost parameters $S_{p}^{k}$ and $S_{0}^{k}$.

Table 2

Techno-economic figures of realised and contracted VSC HVDC back-to-back projects.

\begin{tabular}{lllc}
\hline Project name & $\begin{array}{l}\text { Rated power } \\
(\mathrm{MW})\end{array}$ & $\begin{array}{l}\text { Contracted cost }\left(C_{\mathrm{ref}, i}^{\mathrm{con}}\right) \\
\text { Converters }\left(\mathrm{M} €^{\mathrm{a}}\right)\end{array}$ & Source \\
\hline TresAmigas & 750 & 150.0 & {$[21]$} \\
Mackinac & 350 & 68.0 & {$[22]$} \\
KriegersFlak & 500 & 125.7 & {$[23]$} \\
\hline a Currency other than $€$ was converted with the monthly average exchange rate
\end{tabular}

[24] corresponding to the press releases' date of publication.

The offshore cost parameters are only given by some of the reviewed parameter sets, and they are subject to high variations. Other parameter sets do not consider extra cost for offshore stations, implicitly setting the offshore cost to zero. Madariaga et al. considers a higher cost for the onshore converter than for the offshore converter, implying a negative offshore cost. The linear fit of the considered technology options provided by ENTSO-E and, more specifically, its extrapolation to a power rating of $0 \mathrm{GW}$ lead to a slightly negative $S_{0}^{k}$.

\section{VSC HVDC projects}

Regarding reference cost data for VSC HVDC projects, the sources of information available in the public domain are scarce and sometimes divergent [15]. Therefore, it is difficult to extract sound reference data to validate the parameter sets against. Hence, from publicly available data (i.e. mainly contract values published in suppliers' press releases), the authors obtained cost figures which for some of the projects could also be allocated to the cable system, converter station or in one case to the platform.

This section provides an overview of back-to-back, interconnector and offshore wind connection projects which are referred to in the following evaluation. Only realised or at least contracted projects with published cost figures have been taken into account.

\subsection{Back-to-back}

Table 2 provides an overview of back-to-back projects including their techno-economic parameters.

TresAmigas will be a back-to-back VSC HVDC station in the U.S. state of New Mexico. It will be the first stage of a "SuperStation" connecting the three synchronous zones in the USA. The project has not been built yet but has been awarded to Alstom Grid (now acquired by General Electric Co.), and its contract value is used in this review [21]. 
Table 3

Techno-economic figures of realised and contracted VSC HVDC interconnector projects.

\begin{tabular}{|c|c|c|c|c|c|c|c|c|}
\hline \multirow[t]{2}{*}{ Project name } & \multirow[t]{2}{*}{ Rated power (MW) } & \multicolumn{3}{|c|}{ Line length } & \multicolumn{3}{|c|}{ Contracted cost $\left(C_{\mathrm{ref}, i}^{\mathrm{con}}\right)$} & \multirow[t]{2}{*}{ Source(s) } \\
\hline & & $\mathrm{SMC}^{\mathrm{a}}(\mathrm{km})$ & $\mathrm{UGC}^{\mathrm{a}}(\mathrm{km})$ & $\mathrm{OHL}^{\mathrm{a}}(\mathrm{km})$ & Line $\left(\mathrm{M} €^{\mathrm{b}}\right)$ & Converters $\left(\mathrm{M} €^{\mathrm{b}}\right)$ & Total $\left(\mathrm{M} €^{\mathrm{b}}\right)$ & \\
\hline EstLink1 & 350 & 74 & 31 & - & & 84.8 & 84.8 & [25] \\
\hline EWIC & 500 & 186 & 76 & - & 291.1 & 130.6 & 421.7 & {$[26,27]$} \\
\hline NordBalt & 700 & 400 & 13 & 40 & 268.7 & 169.9 & 438.6 & {$[28,29]$} \\
\hline Åland & 100 & 158 & - & - & & 99.1 & 99.1 & [30] \\
\hline Skagerrak4 & 700 & 138 & 92 & 12 & 127.0 & 131.9 & 258.9 & [31-33] \\
\hline NordLink & 1400 & 516 & 54 & 53 & $936.5^{c}$ & $395.9^{c}$ & $1,332.3$ & {$[34,35]$} \\
\hline NorthSeaLink & 1400 & 720 & 7 & - & 890.0 & 408.9 & 1298.9 & [36-38] \\
\hline COBRA & 700 & 299 & 26 & - & 250.0 & 170.0 & 420.0 & {$[39,40]$} \\
\hline IFA2 & 1000 & 208 & 27 & - & $320.2^{\mathrm{d}}$ & 270.0 & 590.2 & {$[41,42]$} \\
\hline
\end{tabular}

a SubMarine Cable (SMC), UnderGround Cable (UGC), OverHead Line (OHL).

b Currency other than $€$ was converted with the monthly average exchange rate [24] corresponding to the press releases' date of publication.

c When calculating the converter and cable costs of the NordLink project, equal length-specific submarine cable cost for both the Nexans and ABB contract were assumed.

d The HVAC cable on the UK side has been excluded from Prysmian's total contract volume of 350 M€ [42] by assuming a cost-equivalent length factor of 2.5 .

Table 4

Techno-economic figures of realised and contracted VSC HVDC offshore wind connection projects.

\begin{tabular}{|c|c|c|c|c|c|c|c|c|c|}
\hline \multirow[t]{2}{*}{ Project name } & \multirow[t]{2}{*}{ Rated power (MW) } & \multicolumn{3}{|c|}{ Line length } & \multicolumn{4}{|c|}{ Contracted cost $\left(C_{\mathrm{ref}, i}^{\mathrm{con}}\right)$} & \multirow[t]{2}{*}{ Source(s) } \\
\hline & & $\mathrm{SMC}^{\mathrm{a}}(\mathrm{km})$ & $\mathrm{UGC}^{\mathrm{a}}(\mathrm{km})$ & $\mathrm{OHL}^{\mathrm{a}}(\mathrm{km})$ & Line $\left(\mathrm{M} €^{\mathrm{b}}\right)$ & Converters $\left(\mathrm{M} €^{\mathrm{b}}\right.$ & Platform $\left(\mathrm{M} €^{\mathrm{b}}\right)$ & Total $\left(\mathrm{M} €^{\mathrm{b}}\right)$ & \\
\hline BorWin1 & 400 & 125 & 75 & - & \multicolumn{3}{|c|}{$422.8^{c}$} & 422.8 & {$[43]$} \\
\hline BorWin2 & 800 & 125 & 75 & - & 300.0 & \multicolumn{2}{|c|}{$445.3^{c}$} & 745.3 & {$[44,45]$} \\
\hline HelWin1 & 576 & 85 & 45 & - & 150.0 & \multicolumn{2}{|c|}{$595.3^{c}$} & 745.3 & {$[45,46]$} \\
\hline DolWin1 & 800 & 75 & 90 & - & \multicolumn{3}{|c|}{$682.4^{\mathrm{c}}$} & 682.4 & {$[47,48]$} \\
\hline SylWin1 & 864 & 160 & 45 & - & 250.0 & \multicolumn{2}{|c|}{$495.3^{c}$} & 745.3 & [49-51] \\
\hline DolWin2 & 916 & 45 & 92 & - & & 479.6 & $353.0^{c}$ & 832.6 & {$[52,53]$} \\
\hline HelWin2 & 690 & 85 & 45 & - & 200.0 & \multicolumn{2}{|c|}{$645.3^{c, d}$} & 845.3 & {$[54,55]$} \\
\hline DolWin3 & 900 & 83 & 79 & - & 350.0 & \multicolumn{2}{|c|}{800.0} & 1150.0 & [56-58] \\
\hline BorWin3 & 900 & 132 & 29 & - & 250.0 & \multicolumn{2}{|c|}{1000.0} & 1250.0 & [59-61] \\
\hline
\end{tabular}

a SubMarine Cable (SMC), UnderGround Cable (UGC), OverHead Line (OHL).

b Currency other than $€$ was converted with the monthly average exchange rate [24] corresponding to the press releases' date of publication.

c In this context, platform cost include cost increases for ABB's and Siemens' offshore converter stations reported in [62,51] which were equally distributed among the affected projects.

d While Siemens mentions the combined contract value being higher than $500 \mathrm{M} €$ [54], Prysmian Group indicates an amount exceeding 600 M€ [55]; the latter is used here.

Mackinac was built as a back-to-back VSC HVDC station in upper Michigan in order to control the power flow between the upper and lower Peninsulas of Michigan and provide dynamic voltage support. The two directly connected converters were designed, supplied and installed by ABB [22].

KriegersFlak back-to-back HVDC station in Bentwisch will connect the asynchronous AC power grids of TSOs Energinet.dk and 50Hertz Transmission, thereby linking Danish and German power grids. The project will be delivered by ABB [23].

\subsection{Interconnectors}

Table 3 displays a summary of the techno-economic parameters of VSC HVDC interconnector projects relevant for the cost parameter evaluation.

EstLink1 connects the power grids of Finland and Estonia. EastWest-Interconnector (EWIC) links the Irish and UK transmission grids between North Dublin and Wales. NordBalt is a link between the power grids of LITGRID turtas AB in Lithuania and Svenska Kraftnät in Sweden. Aland link is located at the entrance of the Gulf of Bothnia in the Baltic Sea, connecting the power grid of Kraftnät Åland $\mathrm{AB}$ on the Finnish archipelago to the Finnish mainland, which had been previously connected only by an AC cable to the Swedish mainland. At these four HVDC links, the entire system including converters and cables was supplied, installed and commissioned by $\mathrm{ABB}$.

Skagerrak4 was built in parallel to the existing HVDC links Skagerrak1-3 between the power grids of Energinet.dk in Denmark and Statnett in Norway. The two converter stations were supplied by $A B B$ [31]. The submarine cable and the underground cable at the Norwegian end were manufactured and installed by Nexans [32], while the underground cable on the Danish side was supplied by Prysmian Group [33]. As a distinct project feature, Skagerrak4 is operated in bipolar mode with the existing Skagerrak3, which is why only one transmission cable has been laid (half-bipole).

NordLink is the first direct transmission link between the power grids of Norway (Statnett) and Germany (TenneT). The converter stations will be supplied solely by $A B B$, while the corresponding cable system will be manufactured and commissioned by $\mathrm{ABB}$ and Nexans. ABB is responsible for the underground cable on German soil and the German subsea route [34], and Nexans will manufacture and install the HVDC cable system in Norwegian and Danish waters [35].

NorthSeaLink will be a connection between the electricity grids of the UK and Norway. ABB will provide the two VSC HVDC converter stations, one in Blyth, UK and one in Kvilldal, Norway [36]. The responsibility for supplying and installing the submarine cable systems and a short path of underground cable on the UK side of the link rests with Prysmian Group [37]. Nexans will provide the Fjord submarine section as well as the tunnel/lake and underground cable at the Norwegian side [38].

The COpenhagen BRussels Amsterdam or COBRA cable is an HVDC link between the electricity grids of Energinet.dk in Denmark and its Dutch counterpart Tennet TSO. Both converter stations will be supplied by Siemens [39] and the cable system by Prysmian [40].

The IFA2 interconnector project connecting the onshore grids of National Grid in the UK and RTE of France was recently awarded to ABB [41] and Prysmian [42]. ABB will supply both converter stations 
and Prysmian is responsible for delivering the underground and subsea cable systems.

\subsection{Offshore wind connections}

Table 4 displays a summary of the techno-economic parameters of offshore wind connection projects relevant for the cost parameter evaluation.

All currently existing VSC HVDC systems connecting offshore wind power plants to the onshore grid are located in the German exclusive economic zone of the North Sea; moreover, all of them are also in the responsibility of TenneT. Several of the offshore wind connection projects have experienced significant delays and cost overruns. Additional costs caused by the offshore converter stations are reported for both ABB and Siemens [62]. However, no final costs including the overruns have been published for these delayed projects. Given the limited availability of information, the cost figures presented here rely on publicly accessible awarded contractual volumes in press releases. Based on reported additional cost for Siemens and ABB [62,51], the cost overruns are captured and included as far as possible.

BorWin1 was built by ABB as the first HVDC connection for offshore wind, and it is the only one based on two-level-converter technology. The project's commissioning phase took about seven months longer than expected [51]. Even after this extended commissioning phase, problems continued for several years resulting in significant down-times [63-65].

DolWin1 and DolWin2 were entirely built by ABB. These each included the two converter stations, the cable system, and the offshore platform.

BorWin2, HelWin1, SylWin1 and HelWin2 were built by a consortium of Siemens AG and Prysmian Group. Siemens was responsible for the converter stations and the offshore platforms while Prysmian was in charge of the cable system.

DolWin3 was awarded to a consortium of Alstom and Prysmian Group. The project's commissioning is expected in mid-2017.

BorWin3 differs from its preceding projects to the extent that it has been awarded in two separate tenders, one to Siemens (together with Petrofac) and another to Prysmian Group. Initial power transmission on the link is to commence in early 2019.

\section{Evaluation methodology}

Based on the collected data on contracted cost for the reference projects, the reference investment cost for the individual projects is calculated according to Eq. (7).

$$
\begin{aligned}
& C_{\mathrm{ref}, i}=\frac{11}{10} C_{\mathrm{ref}, i}^{\mathrm{con}} \forall i \in I_{\mathrm{B} 2 \mathrm{~B}} \\
& C_{\mathrm{ref}, i}=\frac{5}{4} C_{\mathrm{ref}, i}^{\mathrm{con}} \forall i \in I_{\mathrm{ITC}} \\
& C_{\mathrm{ref}, i}=\frac{5}{4} C_{\mathrm{ref}, i}^{\mathrm{con}} \forall i \in I_{\mathrm{OWC}}
\end{aligned}
$$

These estimated markups are accounting for the difference between reference contractual cost $C_{\mathrm{ref}, i}^{\mathrm{con}}$ and total project reference investment cost $C_{\mathrm{ref}, i}$. These differences are caused by many different factors, including, but not limited to, internal efforts, risk budget, engineering and concession costs, land purchase, construction etc. The markup values are based on $[9,51,66]$ and unquotable personal communication with relevant industry stakeholders.

For each individual reference project, the cost estimation is calculated with each available cost parameter set. These cost estimations are then compared with the reference investment cost and the relative deviation is expressed on a logarithmic scale, expressed by Eq. (8).

$D_{i}^{k}=\log _{2}\left(\frac{C_{\mathrm{est}, i}^{k}}{C_{\mathrm{ref}, i}}\right)$

Relative deviations guarantee an adequate assessment of both small and big projects. Using absolute cost figures would undervalue the correct estimation of smaller projects.

Logarithmic deviations account for the ratio between estimate and reality. It is important to use a logarithmic measure of the deviation to ensure a correct evaluation of both under- and overestimation.

Cost estimations range between the two worst possible estimates $\{0, \infty\}$, which are both equally evaluated on a logarithmic scale $\{-\infty,+\infty\}$. A non-logarithmic (linear) measure would inadequately evaluate them $\{-1,+\infty\}$, creating the wrong impression that zero cost would be a much better estimate than infinite cost.

The non-logarithmic measure would equally evaluate $\{0,2\}$, yielding $\{-1,+1\} .\{2\}$ is by all means not a good estimation, but it still represents a valid result. On the contrary, $\{0\}$ implies that the infrastructure can be deployed at zero cost, which is obviously wrong, leading to over-investments in 'free' assets when a transmission expansion planning optimisation is conducted. The logarithmic measure returns $\{-\infty,+1\}$ for this example, correctly reflecting the practical implications of the two estimates.

As a consequence, the following evaluation of parameter sets employs the relative logarithmic measure, as shown in Eq. (8).

To assess whether a parameter set generally over- or underestimates the cost of the three categories, the mean category deviation of each category has been calculated according to Eq. (9)

$D_{j}^{k}=\frac{1}{\left|I_{j}\right|} \sum_{i}^{I_{j}} D_{i}^{k}$

To assess the performance of the parameter sets for the three project categories, the root-mean-square category error for all projects within a category is calculated, as expressed in Eq. (10).

$E_{j}^{k}=\sqrt{\frac{1}{\left|I_{j}\right|} \sum_{i}^{I_{j}}\left(D_{i}^{k}\right)^{2}}$

To assess the overall performance of the parameter sets, the overall root-mean-square error is calculated, as expressed in Eq. (11):

$E^{k}=\sqrt{\frac{1}{\mathrm{~J} \mid} \sum_{j}^{J}\left(E_{j}^{k}\right)^{2}}$

\section{Evaluation of cost parameter sets}

In this section, the investment model cost parameters in Tables A. 1 and A.2 are related to real-world VSC HVDC project data in Tables 2-4.

\subsection{Back-to-back}

Fig. 4 illustrates the project deviations and category deviation for back-to-back projects.

As a result, the different cost parameter sets reveal deviations in both directions with a slight tendency towards underestimating the costs of the back-to-back projects. Since Imperial College and Torbaghan use a very simple cost model (no node parameters, only branch parameters), both estimate zero investment costs for 


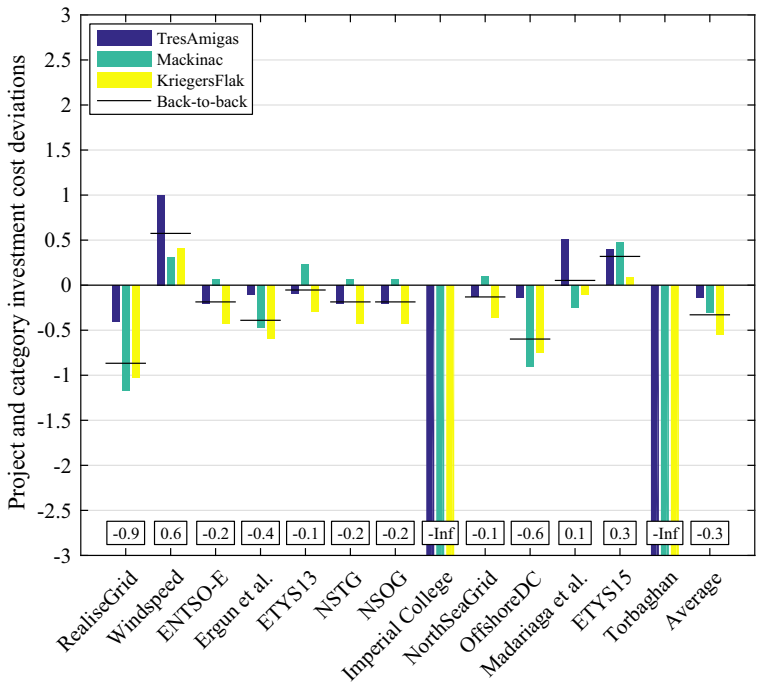

Fig. 4. Deviations for back-to-back projects (category deviation values shown in boxes).

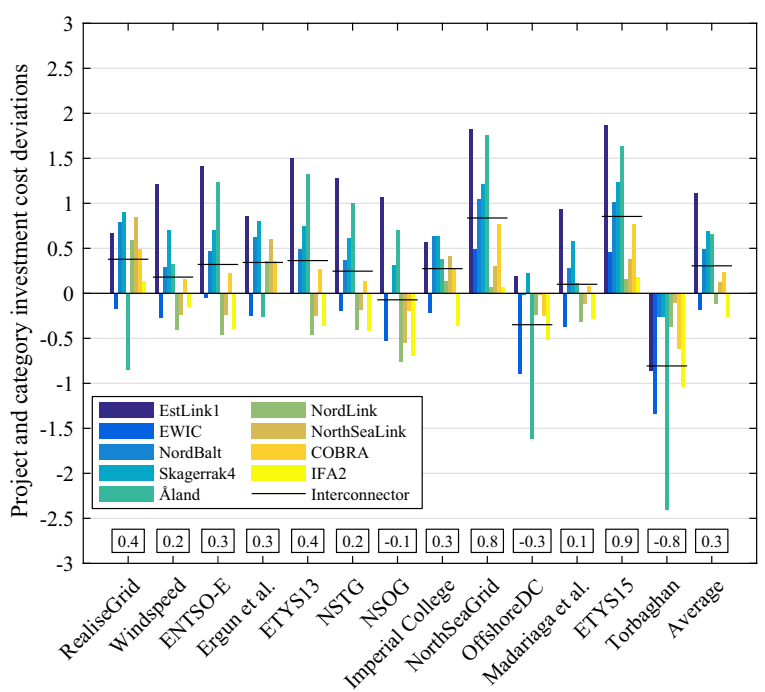

Fig. 5. Deviations for interconnector projects (category deviation values shown in boxes).

back-to-back systems, and consequently show deviations of negative infinity. This clearly shows the limitations of such simple cost models.

\subsection{Interconnectors}

Fig. 5 illustrates the project deviations and category deviation for interconnector projects.

The illustration shows that the majority of cost parameter sets overestimate the investment costs for interconnector projects, most notably EstLink1 and Skagerrak4. That said, Åland project costs are both over- and underestimated which might be due to the fact that it is a comparatively small project, in terms of both length and power rating, which most of the parameter sets do not seem to be well adjusted to. Interestingly, for the interconnector projects in focus, the parameter set of Torbaghan which is only employing the $B_{l p}$ parameter solely underestimates the interconnector projects.

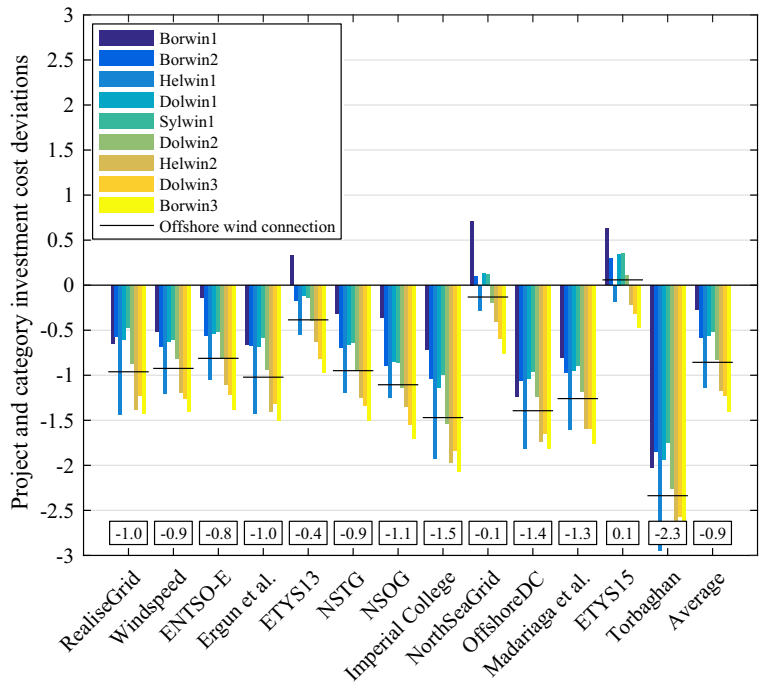

Fig. 6. Deviations for offshore wind connector projects (category deviation values shown in boxes).

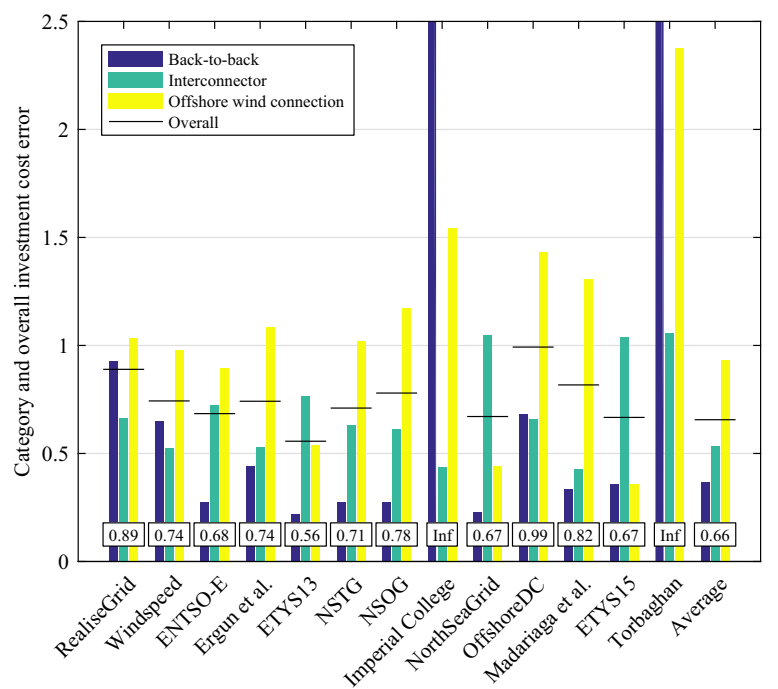

Fig. 7. Evaluation of category errors and overall error (overall error values shown in boxes).

\subsection{Offshore wind connectors}

Fig. 6 illustrates the project deviations and category deviation for offshore wind connector projects.

Most importantly, it can be observed that the majority of the cost model parameter sets significantly underestimate the cost of offshore wind connection projects. Only ETYS13, ETYS15 and NorthSeaGrid reveal smaller deviations.

\subsection{Overall results}

Fig. 7 shows the category error and the overall error for all parameter sets.

When considering back-to-back, interconnector, and offshore wind connection projects altogether, it can be seen that ETYS13 produces the smallest overall investment cost estimation error, followed by the average parameter set. Applying the mean of all the collected parameter sets seems to have yielded reduced uncertainty, delivering rather good results for all three of the considered project categories. 
It is surprising that ETYS13 outperforms ETYS15, giving the impression that the older data source was more accurate than the more recent data. This conclusion, however, is wrong, since the ETYS data sets reflect the technology market prices at a specific moment in time. The ETYS15 cost snapshot could be dominated by an offerdriven-market resulting in high prices, which might not be valid as a long-term average needed for the overall results.

Since the strongly simplified cost models of Imperial College and Torbaghan are not suitable for estimating the cost of back-to-back projects, their overall performance cannot be determined (mathematically leading to an infinite error).

\section{Discussion}

\subsection{Limitations of the methodology}

There are a few simplifications and assumptions limiting the validity of this analysis, as described below.

\subsubsection{Parameter set conversion}

The parameter sets obtained from the literature have been converted into the structure of the linear investment cost model proposed in Section 3. In many cases, this conversion causes the loss of information. For instance, $B_{0}^{k}$ has been estimated to zero if it could not be determined by the available parameter set data. Nevertheless, a conversion of the cost parameter data to fit the proposed linear cost model is unavoidable, since otherwise hardly any comparison would have been possible.

\subsubsection{Line type cost ratios}

A simplified cost ratio between submarine cables and underground cables as well as overhead lines has been used for the evaluation. Assuming different ratios could have minor effects on the parameter evaluation for projects with large underground cable or overhead line sections. However, the simplified cost ratios are necessary to consider the contractual cost taken from press releases.

\subsubsection{Investment cost markup}

A blanket markup on the contractual cost figures has been used when evaluating cost estimates against reference project cost. As previously mentioned, the cost markup is necessary to consider the contractual cost taken from press releases.

\subsubsection{Evolution of cost}

The analysis does not include the cost changes over time, e.g. learning curves or inflation correction for the cost parameter sets. Given the limited overall reference data availability, learning curve effects have been excluded as they are, at least for the moment, impossible to quantify. The inflation correction for the cost parameter sets could have been included. However, as learning curve and inflation effects presumably influence the costs in opposite directions, the accuracy of the results is expected to be better when neglecting both, opposed to neglecting only one of them. It was therefore chosen not to correct the cost parameter sets for inflation.

\subsubsection{Biased validation}

Due to the fact that the limited available reference data used for the validation might or might not be the same as the one used for creating some of the cost parameter sets, a possible methodological flaw could arise. If they, by any chance, coincide while comparing the cost parameter performance against the reference data, the observed amount of deviations could be lower, providing a false sense of reliability for the cost parameter set in question.

\subsection{Accuracy of the reference project cost data}

The investment cost can significantly differ from project to project. Some of the main causes for differences between costs of individual projects are:

- Customised specifications for individual projects.

- HVDC technology market situation (e.g. market power of technology suppliers).

- Offshore operations market situation (e.g. availability of large vessels).

- Prices of raw materials (e.g. steel and copper).

- Location related aspects (e.g. water depth, type of soil and distances to harbours).

- Problems caused by rough conditions offshore.

- Type of client (e.g. commercial company or TSO).

- Differences in risk perception.

Going through the process of collecting information about realised and planned VSC HVDC projects, it became clear that the obtainable cost information in the public domain does not provide a sound and transparent reference to evaluate the parameter sets against, as important data often is proprietary and undisclosed. More specifically, the offshore wind connection projects experienced significant cost overruns incurred by problems and delays concerning the offshore converter stations and their platforms. Detailed information on these cost overruns is not available. With TenneT currently being the only customer for offshore wind connection projects using VSC HVDC technology, the possibilities for data collection are limited. Given the fact that more and more experience is being gained with the offshore wind connection projects, present contractual values might better reflect real costs of offshore converter stations (e.g. the higher contract values of DolWin3 and BorWin3), as compared to older projects (DolWin1 and BorWin1).

The contract values provided in our overview are the only publicly available data to rely on. The additional costs, which are not included in the contract values, have been included using information from $[62,51]$ to the best of the authors' knowledge.

\subsection{Accuracy of the cost parameter sets}

The analysis has shown significant differences between the cost parameter sets. These differences can to some extent be explained by the fact that the different parameter sets:

- have been designed for a variety of purposes;

- focus on specific project categories (e.g. only interconnector projects);

- employ a different level of simplification (e.g. totally neglecting node costs);

- consider phenomena, which are specific for and only valid at the specific point in time of their creation;

- are based on a specific reference project;

- reflect the prices at a specific moment in time;

- are based on different assumptions regarding all the items listed in Section 8.2;

- lack solid reference project cost data to rely on.

This can result in cost parameter sets which are very capable of estimating the cost for a specific type of HVDC projects but fail to do so for another type of HVDC projects. For instance, ETYS15 produces small deviations for the offshore wind connection projects, but at the same time exhibits large deviations for interconnectors. Several other cost parameter sets give better estimations for interconnectors, but significantly underestimate the cost of offshore wind connections. 
It can also lead to cost parameter sets estimating the cost of a specific project very well, but having a large deviation for another project within the same category. As an example, Torbaghan produces good estimates for the high-power long-distance interconnector NordLink, but cannot give an acceptable estimate for the low-power short-distance interconnector Åland. Given the time-evolving nature of technology, older reference data might be outdated. However, as the total amount of published data is very limited, all available data is essential, comprising the risk of using outdated information.

As shown by the comparisons above, the collected cost parameters and thereby obtained cost estimations spread over a wide range, indicating high uncertainty. The evaluation of cost parameter sets reveals that their validity is of heterogeneous nature and the resulting variations of cost estimates are unacceptably large. In summary, the performed analysis substantiates the claim that robust cost information on VSC HVDC infrastructure and reliable cost parameters for VSC HVDC investment models are still not available.

\section{Conclusion}

VSC HVDC transmission infrastructure cost data sets have been gathered from literature, compared to each other, and evaluated against cost data from real reference projects.

The Electricity Ten Year Statement 2013 [8] showed the best overall performance, followed by the average parameter set. Applying the mean of all the collected parameter sets seems to have yielded reduced uncertainty, delivering rather good results for all three of the considered project categories.

Regarding all three types of VSC HVDC infrastructure (back-toback, interconnector, and offshore wind connection), this review can provide a profound basis for future grid investment analyses. Moreover, future research can benefit from these contributions when further reference data reviews and new cost parameter sets are pursued.

Clearly, both the availability of reliable cost reference data and the validity of investment model cost parameters need continuing attention. The next step is to determine a new cost parameter set based on the reference cost data which has been obtained. For instance, by carefully applying a component-based fitting (i.e. converter stations, cable system and offshore converter platform), a potentially more accurate representation of VSC HVDC transmission infrastructure cost could be achieved.

\section{Acknowledgements}

The work has been performed in the framework of the NSON Initiative, the IRPWind project, and NOWITECH. Funding has come from NOWITECH, the German "North Sea Offshore Network" (NSON-DE) project, financed as part of the funding initiative "Zukunftsfähige Stromnetze" (FKZ 0325576H) by the German Federal Ministry for Economic Affairs and Energy (BMWi) and cooperation has been facilitated by the IRP Mobility Programme.

\section{Appendix A. Cost parameter set data}

The investment cost parameter sets which have been gathered from the aforementioned references and the adapted version of these parameter sets (converted to fit the here-introduced cost model format) are given in the appendix. The branch parameters are given in Table A.1 and the node parameters are given in Table A.2.

Table A.1

Branch cost model parameters from previously published cost parameter data.

\begin{tabular}{|c|c|c|c|c|c|c|c|}
\hline Name & Option/variant & Cost & Unit & $\begin{array}{l}B_{l p}^{k} \\
(\mathrm{M} € / \mathrm{GW} \mathrm{km})\end{array}$ & $\begin{array}{l}B_{l}^{k} \\
(\mathrm{M} € / \mathrm{km})\end{array}$ & $B_{0}^{k}(\mathrm{M} €)$ & Source \\
\hline RealiseGrid (2011) & $\begin{array}{l}700 \mathrm{MW} \\
1000 \mathrm{MW} \\
1200 \mathrm{MW}\end{array}$ & $\begin{array}{l}1.90 \\
2.60 \\
3.20\end{array}$ & $\begin{array}{l}\mathrm{M} € / \mathrm{km} \\
\mathrm{M} € / \mathrm{km} \\
\mathrm{M} € / \mathrm{km}\end{array}$ & 2.58 & 0.07 & 0.00 & [4] \\
\hline WindSpeed $^{g}$ (2011) & $\begin{array}{l}600 \mathrm{MW} \\
\text { Installation } \\
\text { Mobilisation }\end{array}$ & $\begin{array}{l}0.40 \\
0.36 \\
5.00\end{array}$ & $\begin{array}{l}\mathrm{M} € / \mathrm{km} \\
\mathrm{M} € / \mathrm{km} \\
\mathrm{M} €\end{array}$ & 0.33 & 0.56 & 5.00 & [5] \\
\hline ENTSO-E ${ }^{\mathrm{a}}$ (2011) & $\begin{array}{l}850 \mathrm{MW} \\
967 \mathrm{MW} \\
1069 \mathrm{MW} \\
1133 \mathrm{MW} \\
\text { Installation }\end{array}$ & $\begin{array}{l}0.43 \\
0.43 \\
0.46 \\
0.53 \\
0.91\end{array}$ & $\begin{array}{l}M € / \mathrm{km} \\
M € / \mathrm{km} \\
M € / \mathrm{km} \\
M € / \mathrm{km} \\
M € / \mathrm{km}\end{array}$ & 0.33 & 1.05 & 0.00 & [6] \\
\hline Ergun et al. ${ }^{\mathrm{b}}$ (2012) & $\begin{array}{l}450 \mathrm{MW} \\
500 \mathrm{MW} \\
550 \mathrm{MW} \\
900 \mathrm{MW}\end{array}$ & $\begin{array}{l}0.98 \\
1.07 \\
1.17 \\
1.85\end{array}$ & $\begin{array}{l}\mathrm{M} € / \mathrm{km} \\
\mathrm{M} € / \mathrm{km} \\
\mathrm{M} € / \mathrm{km} \\
\mathrm{M} € / \mathrm{km}\end{array}$ & 2.05 & 0.11 & 0.00 & [7] \\
\hline ETYS $^{a}(2013)$ & $\begin{array}{l}855 \mathrm{MW} \\
967 \mathrm{MW} \\
1069 \mathrm{MW} \\
1133 \mathrm{MW} \\
\text { Installation }\end{array}$ & $\begin{array}{l}0.32 \\
0.33 \\
0.34 \\
0.38 \\
0.59\end{array}$ & $\begin{array}{l}M € / \mathrm{km} \\
M € / \mathrm{km} \\
M € / \mathrm{km} \\
M € / \mathrm{km} \\
M € / \mathrm{km}\end{array}$ & 0.29 & 1.06 & 0.00 & [8] \\
\hline NSTG $^{c, g}(2013)$ & $1200 \mathrm{MW}$ & 1.47 & $\mathrm{M} € / \mathrm{km}$ & 0.61 & 0.74 & 0.00 & [9] \\
\hline NSOGa $^{\mathrm{a}}(2014)$ & $\begin{array}{l}403 \mathrm{MW} \\
1373 \mathrm{MW} \\
1510 \mathrm{MW} \\
2146 \mathrm{MW} \\
\text { Installation }\end{array}$ & $\begin{array}{l}0.60 \\
1.32 \\
1.12 \\
1.47 \\
0.40\end{array}$ & $\begin{array}{l}M € / \mathrm{km} \\
M € / \mathrm{km} \\
M € / \mathrm{km} \\
M € / \mathrm{km} \\
M € / \mathrm{km}\end{array}$ & 0.50 & 0,45 & 0.00 & {$[11]$} \\
\hline
\end{tabular}


Table A.1 (Continued)

\begin{tabular}{|c|c|c|c|c|c|c|c|}
\hline Name & Option/variant & Cost & Unit & $\begin{array}{l}B_{l p}^{k} \\
(\mathrm{M} € / \mathrm{GW} \mathrm{km})\end{array}$ & $\begin{array}{l}B_{l}^{k} \\
(\mathrm{M} € / \mathrm{km})\end{array}$ & $B_{0}^{k}(\mathrm{M} €)$ & Source \\
\hline \multirow[t]{2}{*}{ Imperial College $^{\mathrm{d}}(2014)$} & $\begin{array}{l}\text { Fixed cable costs, } \\
\text { annuity }^{c}\end{array}$ & 0.07 & $\mathrm{M} € / \mathrm{km} \cdot \mathrm{a}$ & & & & {$[12]$} \\
\hline & $\begin{array}{l}\text { Variable cable costs, } \\
\text { annuity }^{c}\end{array}$ & 120.00 & $\mathrm{M} € / \mathrm{GW} \mathrm{km} \mathrm{a}$ & 1.50 & 0.87 & 0.00 & \\
\hline \multirow[t]{4}{*}{ NorthSeaGrid (2015) } & $1400 \mathrm{MW}$ & 0.57 & $\mathrm{M} € / \mathrm{km}$ & & & & [13] \\
\hline & $1000 \mathrm{MW}$ & 0.43 & $\mathrm{M} € / \mathrm{km}$ & & & & \\
\hline & $700 \mathrm{MW}$ & 0.32 & $\mathrm{M} € / \mathrm{km}$ & & & & \\
\hline & Installation & 1.78 & $\mathrm{M} € / \mathrm{km}$ & 0.35 & 1.85 & 0.00 & \\
\hline \multirow[t]{3}{*}{ OffshoreDC ${ }^{c}$ (2015) } & Low & 1.10 & $\mathrm{M} € / \mathrm{GW} \mathrm{km}$ & & & & {$[14]$} \\
\hline & Medium & 1.30 & $\mathrm{M} € / \mathrm{GW} \mathrm{km}$ & & & & \\
\hline & High & 1.50 & $\mathrm{M} € / \mathrm{GW} \mathrm{km}$ & 1.30 & 0.00 & 0.00 & \\
\hline \multirow[t]{6}{*}{ Madariaga et al. ${ }^{e, g}$ (2015) } & $100 \mathrm{~km}, 900 \mathrm{MW}$ & 116.75 & $M €$ & & & & [15] \\
\hline & $110 \mathrm{~km}, 900 \mathrm{MW}$ & 128.03 & $M €$ & & & & \\
\hline & $120 \mathrm{~km}, 900 \mathrm{MW}$ & 139.29 & $M €$ & & & & \\
\hline & $130 \mathrm{~km}, 900 \mathrm{MW}$ & 150.56 & $M €$ & & & & \\
\hline & $140 \mathrm{~km}, 900 \mathrm{MW}$ & 161.83 & $M €$ & & & & \\
\hline & $150 \mathrm{~km}, 900 \mathrm{MW}$ & 173.10 & $M €$ & 0.63 & 0.56 & 4.06 & \\
\hline \multirow[t]{5}{*}{ ETYS (2015) } & $600 \mathrm{MW}^{\mathrm{f}}$ & 0.65 & $\mathrm{M} € / \mathrm{km}$ & & & & {$[16]$} \\
\hline & $800 \mathrm{MW}^{\mathrm{f}}$ & 0.75 & $\mathrm{M} € / \mathrm{km}$ & & & & \\
\hline & $1000 \mathrm{MW}^{\mathrm{f}}$ & 0.86 & $\mathrm{M} € / \mathrm{km}$ & & & & \\
\hline & $1200 \mathrm{MW}^{\mathrm{f}}$ & 1.03 & $\mathrm{M} € / \mathrm{km}$ & & & & \\
\hline & Installation & 1.19 & $\mathrm{M} € / \mathrm{km}$ & 0.63 & 1.45 & 0.00 & \\
\hline \multirow[t]{2}{*}{ Torbaghan ${ }^{c}$ (2016) } & Interconnector & 1.48 & $\mathrm{M} € / \mathrm{GW} \mathrm{km}$ & & & & [17] \\
\hline & & & & 1.48 & 0.00 & 0.00 & \\
\hline
\end{tabular}

a Transmittable power is derived from the cross-section of the cable according to [16].

b The proposed non-linear model is used to create cost data for the respective transmissible power. A voltage level of $320 \mathrm{kV}$ is assumed.

c The provided cost parameters already fit the cost model coefficients.

d Personal contact to the author revealed that the fixed cable cost are annuitised as well. A discount rate of $5 \%$ p.a. is specified in the source and a service life of 20 a is assumed to convert annuities to investment costs.

e The cost for the land cable section is deducted from total cable cost.

f The cost figures are the average of all given HVDC extruded offshore cable options (aluminum and copper conductor).

$g$ The provided source only relies on a single branch option. Given the purpose of this review, after thorough consideration of different options, the branch option's cost have been equally distributed to the $B_{l p}$ and $B_{l}$ parameters.

Table A.2

Node and offshore cost model parameters from previously published cost parameter data.

\begin{tabular}{|c|c|c|c|c|c|c|c|c|}
\hline Name & Option/variant & Cost & Unit & $N_{p}^{k}(\mathrm{M} € / \mathrm{GW})$ & $N_{0}^{k}(\mathrm{M} €)$ & $S_{p}^{k}(\mathrm{M} € / \mathrm{GW})$ & $S_{0}^{k}(\mathrm{M} €)$ & Source \\
\hline \multirow[t]{2}{*}{ RealiseGrid ${ }^{\mathrm{a}}$ (2011) } & Converter costs & 83.00 & $\mathrm{M} € / \mathrm{GW}$ & & & & & \multirow[t]{2}{*}[4]{} \\
\hline & Platform costs & 28.00 & $\mathrm{M} €$ & 83.00 & 0.00 & 0.00 & 28.00 & \\
\hline \multirow[t]{4}{*}{ Windspeed $^{\mathrm{a}}(2011)$} & $600 \mathrm{MW}$, off & 143.40 & $\mathrm{M} €$ & & & & & \multirow[t]{4}{*}[5]{} \\
\hline & Installation, off & 23.80 & $\mathrm{M} €$ & & & & & \\
\hline & $600 \mathrm{MW}$, on & 129.60 & $\mathrm{M} €$ & & & & & \\
\hline & Installation, on & 6.50 & $\mathrm{M} €$ & 216.00 & 6.50 & 23.00 & 17.30 & \\
\hline \multirow[t]{6}{*}{ ENTSO-E (2011) } & VSC $500 \mathrm{MW}$ & 83.50 & $\mathrm{M} €$ & & & & & \multirow[t]{6}{*}{ [6] } \\
\hline & VSC $850 \mathrm{MW}$ & 101.50 & $\mathrm{M} €$ & & & & & \\
\hline & VSC $1250 \mathrm{MW}$ & 135.50 & $\mathrm{M} €$ & & & & & \\
\hline & VSC $2000 \mathrm{MW}$ & 170.00 & $\mathrm{M} €$ & & & & & \\
\hline & Platform $400 \mathrm{MW}$ & 66.60 & $\mathrm{M} €$ & & & & & \\
\hline & Platform $800 \mathrm{MW}$ & 140.00 & $\mathrm{M} €$ & 58.90 & 54.90 & 183.50 & -6.80 & \\
\hline \multirow[t]{3}{*}{ Ergun et al. ${ }^{\text {b }}$ (2012) } & Power-dependent converter station cost & 90.00 & $\mathrm{M} € / \mathrm{GW}$ & & & & & \multirow[t]{3}{*}{ [7] } \\
\hline & Fixed onshore converter station costs & 18.00 & $M €$ & & & & & \\
\hline & Fixed offshore converter station costs & 42.00 & $\mathrm{M} €$ & 90.00 & 18.00 & 0.00 & 24.00 & \\
\hline \multirow[t]{7}{*}{ ETYS (2013) } & $500 \mathrm{MW}$ VSC & 61.26 & $\mathrm{M} €$ & & & & & \multirow[t]{7}{*}[8]{} \\
\hline & $850 \mathrm{MW}$ VSC & 80.21 & $\mathrm{M} €$ & & & & & \\
\hline & $1250 \mathrm{MW}$ VSC & 98.34 & $\mathrm{M} €$ & & & & & \\
\hline & $2000 \mathrm{MW}$ VSC & 124.54 & $\mathrm{M} €$ & & & & & \\
\hline & $1000 \mathrm{MW}$ platform & 237.40 & $\mathrm{M} €$ & & & & & \\
\hline & $1250 \mathrm{MW}$ platform & 268.43 & $\mathrm{M} €$ & & & & & \\
\hline & 2000 MW platform & 384.11 & $\mathrm{M} €$ & 60.80 & 63.17 & 216.60 & 143.66 & \\
\hline \multirow[t]{3}{*}{ NSTG $^{c}$ (2013) } & Pair of 1200 MW VSC, fixed cost & 110.00 & $\mathrm{M} €$ & & & & & \multirow[t]{3}{*}[9,10]{} \\
\hline & Pair of 1200 MW VSC, variable cost & 117.80 & $\mathrm{M} € / \mathrm{GW}$ & & & & & \\
\hline & $1200 \mathrm{MW}$ platform & 157.00 & $\mathrm{M} €$ & 58.90 & 54.90 & 130.83 & 0.00 & \\
\hline \multirow[t]{5}{*}{ NSOG (2014) } & Platform & 111.30 & $\mathrm{M} €$ & & & & & \multirow[t]{5}{*}{ [11] } \\
\hline & VSC $500 \mathrm{MW}$ & 83.50 & $\mathrm{M} €$ & & & & & \\
\hline & VSC $850 \mathrm{MW}$ & 101.50 & $\mathrm{M} €$ & & & & & \\
\hline & VSC $1250 \mathrm{MW}$ & 135.50 & $\mathrm{M} €$ & & & & & \\
\hline & VSC $2000 \mathrm{MW}$ & 170.00 & $\mathrm{M} €$ & 58.90 & 54.90 & 0.00 & 111.30 & \\
\hline
\end{tabular}


Table A.2 (Continued)

\begin{tabular}{|c|c|c|c|c|c|c|c|c|}
\hline Name & Option/variant & Cost & Unit & $N_{p}^{k}(\mathrm{M} € / \mathrm{GW})$ & $N_{0}^{k}(\mathrm{M} €)$ & $S_{p}^{k}(\mathrm{M} € / \mathrm{GW})$ & $S_{0}^{k}(\mathrm{M} €)$ & Source \\
\hline \multirow[t]{2}{*}{ Imperial College (2014) } & - & - & - & & & & & {$[12]$} \\
\hline & & & & 0.00 & 0.00 & 0.00 & 0.00 & \\
\hline \multirow[t]{4}{*}{ NorthSeaGrid (2015) } & $1400 \mathrm{MW}$ platform & 340.00 & $M €$ & & & & & [13] \\
\hline & $1000 \mathrm{MW}$ platform & 290.00 & $M €$ & & & & & \\
\hline & $1400 \mathrm{MW}$ VSC & 145.00 & $M €$ & & & & & \\
\hline & $1000 \mathrm{MW}$ VSC & 119.00 & $\mathrm{M} €$ & 65.00 & 54.00 & 125.00 & 218.95 & \\
\hline \multirow[t]{3}{*}{ OffshoreDC ${ }^{\text {a }}$ (2015) } & Onshore station (Medium) & 100.00 & $\mathrm{M} € / \mathrm{GW}$ & & & & & [14] \\
\hline & Offshore station 50\% (Medium) & 150.00 & $\mathrm{M} € / \mathrm{GW}$ & & & & & \\
\hline & Offshore station 100\% (Medium) & 200.00 & $\mathrm{M} € / \mathrm{GW}$ & 100.00 & 0.00 & 75.00 & 0.00 & \\
\hline \multirow[t]{2}{*}{ Madariaga et al. (2015) } & 900 MW Onshore HVDC Converter & 141.38 & $\mathrm{M} €$ & & & & & [15] \\
\hline & 900 MW Offshore HVDC Converter & 127.88 & $\mathrm{M} €$ & 157.00 & 0.00 & -14.93 & 0.00 & \\
\hline \multirow[t]{17}{*}{ ETYS (2015) } & 800 MW VSC offshore & 64.43 & $M €$ & & & & & [16] \\
\hline & 1000 MW VSC offshore & 85.06 & $\mathrm{M} €$ & & & & & \\
\hline & 1200 MW VSC offshore & 116.91 & $M €$ & & & & & \\
\hline & 1800 MW VSC offshore & 130.30 & $\mathrm{M} €$ & & & & & \\
\hline & 2200 MW VSC offshore & 161.07 & $M €$ & & & & & \\
\hline & $800 \mathrm{MW}$ VSC onshore & 77.82 & $M €$ & & & & & \\
\hline & $1000 \mathrm{MW}$ VSC onshore & 88.32 & $M €$ & & & & & \\
\hline & $1200 \mathrm{MW}$ VSC onshore & 96.64 & $M €$ & & & & & \\
\hline & 1800 MW VSC onshore & 121.25 & $\mathrm{M} €$ & & & & & \\
\hline & 2200 MW VSC onshore & 157.81 & $M €$ & & & & & \\
\hline & $1000 \mathrm{MW}$ platform & 296.80 & $M €$ & & & & & \\
\hline & $1250 \mathrm{MW}$ platform & 330.28 & $\mathrm{M} €$ & & & & & \\
\hline & $1500 \mathrm{MW}$ platform & 402.67 & $\mathrm{M} €$ & & & & & \\
\hline & $1750 \mathrm{MW}$ platform & 459.68 & $M €$ & & & & & \\
\hline & $2000 \mathrm{MW}$ platform & 521.21 & $\mathrm{M} €$ & & & & & \\
\hline & $2250 \mathrm{MW}$ platform & 583.64 & $M €$ & & & & & \\
\hline & $2500 \mathrm{MW}$ platform & 650.61 & $\mathrm{M} €$ & 103.00 & 62.60 & 475.90 & 46.07 & \\
\hline \multirow[t]{2}{*}{ Torbaghan (2016) } & - & - & - & & & & & [17] \\
\hline & & & & 0.00 & 0.00 & 0.00 & 0.00 & \\
\hline
\end{tabular}

a The provided cost parameters already fit the cost model coefficients.

b The proposed non-linear model is used to create cost data for the respective transmissible power, a voltage level of $320 \mathrm{kV}$ is assumed.

c Platform costs are not considered in this study.

\section{References}

[1] J. Gorenstein Dedecca, R.A. Hakvoort, A review of the North Seas offshore grid modeling: current and future research, Renew. Sustain. Energy Rev. 60 (2016) 129-143, http://dx.doi.org/10.1016/j.rser.2016.01.112.

[2] V.J. Schwanitz, A. Wierling, Offshore wind investments - realism about cost developments is necessary, Energy 106 (2016) 170-181, http://dx.doi.org/10. 1016/j.energy.2016.03.046.

[3] T.K. Vrana, R.E. Torres-Olguin, Report: Technology Perspectives of the North Sea Offshore and Storage Network (NSON), 2015.

[4] A. L'Abbate, G. Migliavacca, Review of costs of transmission infrastructures, including cross border connections: REseArch, methodoLogles and technologies for the effective development of pan-European key GRID infrastructures to support the achievement of a reliable, competitive and sustainable electricity supply (REALISEGRID): Deliverable d3.3.2, 2011, URL http://realisegrid.rse-web.it.

[5] J. Jacquemin, D. Butterworth, C. Garret, N. Baldock, A. Henderson, Windspeed D2.2: Inventory of Location Specific Wind Energy Cost, 2011.

[6] ENTSO-E, Offshore Transmission Technology, 2011.

[7] H. Ergun, D. van Hertem, R. Belmans, Transmission system topology optimization for large-scale offshore wind integration, IEEE Trans. Sustain. Energy 3 (4) (2012) 908-917, http://dx.doi.org/10.1109/TSTE.2012.2199341.

[8] P. Sheppard, Electricity Ten Year Statement - Appendix E, 2013.

[9] F.D.J. Nieuwenhout, M. van Hout, Cost, Benefits, Regulations and Policy Aspects of a North Sea Transnational Grid, 2013, URL http://www.nstgproject.nl/uploads/media/9_ECN-E-13-065_NSTG_WP7_Cost_benefits_ regulations_policy_aspects.pdf.

[10] J.T.G. Pierik, North Sea Transnational Grid: Evaluation of NSTG Options (WP2), 2014, URL http://www.nstg-project.nl/uploads/media/2_ECN-E-14-003NSTG_WP2_Evaluation_NSTG_Options.pdf.

[11] S. Cole, P. Martinot, S. Rapoport, G. Papaefthymiou, V. Gori, Study of the Benefits of a Meshed Offshore Grid in Northern Seas Region: Final Report, 2014, URL http://ec.europa.eu/energy/infrastructure/studies/doc/2014_nsogreport.pdf.

[12] G. Strbac, R. Moreno, I. Konstantelos, D. Pudjianto, M. Aunedi, Strategic Development of North Sea Grid Infrastructure to Facilitate Least-Cost Decarbonisation, 2014.

[13] A. Flament, P. Joseph, G. Gerdes, L. Rehfeldt, A. Behrens, A. Dimitrova, F. Genoese, I. Gajic, M. Jafar, N. Tidemand, Y. Yang, J. Jansen, F. Nieuwenhout, K. Veum, I. Konstantelos, D. Pudjianto, G. Strbac, NorthSeaGrid Final Report, 2015.
[14] N. Helistö, V.C. Tai, OffshoreDC: Electricity Market and Power Flow Impact of Wind Power and DC Grids in the Baltic Sea: Research Report, 2015, URL http://www.vtt.fi/inf/julkaisut/muut/2015/VTT-R-05999-15.pdf.

[15] A. Madariaga, N. MacLeod, Offshore HVDC risk perceptions: are they driving investments appropriately? in: Energynautics GmbH (Ed.), 14th Wind Integration Workshop, Brussels (2015).

[16] R. Smith, Electricity Ten Year Statement - Appendix E, 2015.

[17] S. Shariat Torbaghan, Transmission Expansion Planning of Transnational Offshore Grids: A Techno-Economic and Legal Approach Case Study of the North Sea Offshore Grid, Dissertation, Delft University of Technology, Delft, 2016, http://dx.doi.org/10.4233/uuid:4a3d986d-ec49-4b1e-8ac2393885d9d026.

[18] H.G. Svendsen, Planning tool for clustering and optimised grid connection of offshore wind farms, Energy Procedia 35 (2013) 297-306, http://dx.doi.org/ 10.1016/j.egypro.2013.07.182.

[19] T. Trötscher, M. Korpås, A framework to determine optimal offshore grid structures for wind power integration and power exchange, Wind Energy 14 (8) (2011) 977-992, http://dx.doi.org/10.1002/we.461.

[20] T.K. Vrana, Review of HVDC Component Ratings: XLPE Cables and VSC Converters, IEEE EnergyCon, Leuven, 2016.

[21] Alstom Grid Press Releases, Alstom Grid will provide Tres Amigas LLC in the USA with first-of-its-kind Smart Grid SuperStation (21.04.2011).

[22] ABB Press Releases, ABB wins $\$ 90$ million power order to improve grid stability in Michigan: HVDC Light system to facilitate power flow control and integration of renewables (23.02.2012).

[23] ABB Press Releases, ABB wins \$ 140 million order to boost integration of renewables in Europe: HVDC converter station to link Danish and German power grids and enhance energy security (10.03.2016).

[24] X-Rates, Exchange Rate Average, 2016, URL http://www.X-rates.com/average.

[25] ABB Press Releases, ABB wins bid for underground power link between Estonia and Finland: Unique HVDC Light technology helps to expand Trans-European Network (04.02.2005).

[26] ABB Press Releases, ABB wins power transmission order worth $\$ 550$ million from Irish grid operator: Ireland-U.K. power link to strengthen grid reliability and security of supply (29.03.2009).

[27] L. Brand, R. de Silva, E. Bebbington, K. Chilukuri, Grid West Project: HVDC Technology Review, 2014, URL http://www.eirgridgroup.com/site-files/ library/EirGrid/Grid-West-HVDC-Technology-Review-Report-PSC.pdf.

[28] ABB Press Releases, ABB wins \$ 580-million power transmission order in Europe: New transmission link strengthens integration of Baltic energy markets with northern Europe (20.12.2010). 
[29] Reuters, UPDATE 1-ABB wins $\$ 580$ mln Nordic-Baltic power order (20.12.2010). URL http://uk.reuters.com.

[30] ABB Press Releases, ABB wins \$130-million HVDC order for subsea power transmission link in Finland: HVDC light technology secures power supply and grid reliability to Finnish archipelago (13.12.2012).

[31] ABB Press Releases, ABB wins \$ 180 million order for Norway-Denmark power transmission link (10.02.2011).

[32] N.P. Releases, Nexans wins 87 million Euro contract for Sagerrak 4 subsea HVDC power cable between Denmark and Norway (07.01.2011).

[33] Prysmian Group Press Releases, Official inauguration of the Skagerrak 4 electrical interconnection between Norway and Denmark (12.03.2015).

[34] ABB Press Releases, ABB wins $\$ 900$ million order to connect Norwegian and German power grids: NordLink project will be Europe's longest HVDC power grid interconnection and enable the transmission of 1,400 megawatts (MW) of renewable energy (19.03.2015).

[35] Nexans, NordLink HVDC interconnector between Norway and Germany will use Nexans' subsea power cables (12.02.2015). URL http://www.nexans.com/ eservice/Corporate-en/navigatepub_325297_34239/NordLink_HVDC interconnector_between_Norway_and_Ge.html.

[36] ABB Press Releases, ABB wins $\$ 450$ million order for Norway-UK HVDC interconnection (14.07.2015)

[37] Prysmian Group Press Releases, Prysmian, new contract worth around $€ 550$ $M$ for an HVDC submarine interconnector between Norway and the UK (14.07.2015).

38] Nexans Press Releases, NSN Link will interconnect Nordic and British energy markets with the world's longest subsea power link incorporating Nexans' HVDC cable technology (14.07.2015).

39] Siemens AG Press Releases, Siemens wins order for HVDC link between Denmark and Holland (01.02.2016).

[40] Prysmian Group Press Releases, Prysmian secures contract worth around $€$ $250 \mathrm{M}$ for a submarine power cable link between the Netherlands and Denmark (01.02.2016).

[41] ABB Press Releases, ABB selected for a $€ 270$ million order for UK-France power link: ABB is awarded the HVDC converter stations for the IFA2 interconnection (07.04.2017).

[42] Prysmian Group Press Releases, The project worth around $€ 350 \mathrm{M}$ has been awarded to Prysmian by a joint venture between French RTE and UK National Grid IFA2 LTD (07.04.2017).

[43] ABB Press Releases, ABB wins power order worth more than $\$ 400$ million for world's largest offshore wind farm: Innovative technology will connect wind-generated electric power to grid (18.09.2007).

44] Siemens AG Press Releases, Siemens receives order from transpower to connect offshore wind farms via HVDC link: Order worth more than EUR500 million for the consortium (11.06.2010).

[45] Prysmian Group Press Releases, Prysmian secures a further major project worth more than $€ 150 \mathrm{M}$ from German Transpower for the HelWin1 grid connection of offshore wind farms (16.07.2010).

[46] Siemens AG Press Releases, Siemens erhält von transpower weiteren Auftrag zur Anbindung von Offshore-Windenergieanlagen: Auftragswert für Konsortium liegt bei rund einer halben Milliarde Euro (16.07.2010).
[47] ABB Press Releases, ABB wins order for offshore wind power connection worth around \$ 700 million: HVDC Light transmission link will connect three North Sea wind farms to German power grid (16.07.2010).

[48] A. Abdalrahman, E. Isabegovic, DolWin1 - challenges of connecting offshore wind farms, 2016 IEEE International Energy Conference (ENERGYCON) (2016) 1-10, http://dx.doi.org/10.1109/ENERGYCON.2016.7513981.

[49] Siemens AG Press Releases, Green power from the North Sea: Siemens to install grid link for DanTysk offshore wind farm (26.01.2011).

[50] Prysmian Group Press Releases, Prysmian secures SylWin 1 project by TenneT for the cable connection of offshore wind farms in the North Sea to the German power grid (26.01.2011)

[51] Fichtner, GGSC, Beschleunigungs- und Kostensenkungspotenziale bei HGÜ-Offshore-Netzanbindungsprojekten - Langfassung (2016).

[52] ABB Press Releases, ABB wins \$ 1 billion order for offshore wind power connection: HVDC Light transmission link will connect North Sea wind farms to German power grid (02.08.2011)

[53] M. Sprenger, Kontrakt til 1,7 milliarder, Teknisk Ukeblad. URL http://www.tu. no/artikler/kontrakt-til-1-7-milliarder/245784.

[54] Siemens AG Press Releases, Siemens brings HelWin cluster windfarm on line: Offshore HVDC platform for low-loss transmission to the onshore grid (02.08.2011).

[55] Prysmian Group Press Releases, Prysmian secures HelWin2 project worth in excess of $€ 200 \mathrm{M}$ for the grid connection of Offshore Wind Farms in Germany (01.08.2011)

[56] Handelsblatt, Offshore-Plattform, Neuer Großauftrag für Nordic Yards, Handelsblatt. URL http://www.handelsblatt.com.

[57] Prysmian Group Press Releases, Prysmian secures DolWin3 project worth in excess of $€ 350 \mathrm{M}$ for the grid connection of offshore wind farms in Germany (26.02.2013).

[58] Alstom Press Releases, Offshore-Windenergie, Vergabe von DolWin3 bringt Energiewende voran (26.02.2013).

[59] Siemens AG Press Releases, Siemens receives major order for BorWin3 North Sea grid connection from TenneT (15.04.2014).

[60] Siemens AG, Hauptversammlung der Siemens AG: Rede Joe Kaeser. URL http://www.siemens.com/press/pool/de/events/2015/corporate/2015-Q1/ 2015-HV-rede-kaeser.pdf.

[61] Prysmian Group Press Releases, Prysmian Secures BorWin3 Project Worth In Excess Of $€ 250 \mathrm{M}(15.04 .2014)$.

[62] Manager Magazin, Neue Verzögerung bei ABBs Umspannplattformen auf hoher See, Manager Magazin. URL http://www.manager-magazin.de.

[63] S. Knight, Bard 1 transmission problems continue - Wind Power Offshore, 2014.

[64] U. Leuschner, Netzanbindung akzeptiert 'schmutzigen' Strom von Offshore-Windpark nicht - Energie-Chronik, 2014

[65] C. Gerlach, Kein Strom: Letzte Chance für BARD Offshore 1 - NDR. de, 2014.

[66] reNEWS Ltd, NordLink seeks EIB cash: Partners TenneT, Statnett and KfW apply for $€ 800 \mathrm{~m}$ loan for $1.4 \mathrm{GW}$ link (02.11.2016). URL http://renews.biz/. 